\title{
Mine relinquishment policy in Australia
}

\author{
CD Tiemann Curtin University, and Independence Group NL, Australia \\ MC McDonald Society for Ecological Restoration Australasia, Australia \\ G Middle Curtin University, Australia \\ KW Dixon Curtin University, Australia
}

\begin{abstract}
The profile of mine rehabilitation and closure continues to gain momentum in Australia, with an increasing focus by governments, industry and the broader community on a range of mine closure related topics. Despite decades of mine closure research and rehabilitation activities, there are limited examples within Australia of mining operations closing successfully and allowing relinquishment of mine tenure. A review of policy across Australia demonstrates that no clear pathway to relinquishment exists within mine closure legislation. While policy gaps contribute to the limited examples of successful relinquishment, defined in this paper as the transfer of liability, there are a number of additional roadblocks. A major one being the reality of residual risk and liability existing after a mine has been successfully closed. Closing a mine is an investment decision, with mining executives and boards requiring certainty of process and outcome to invest in closure. Moving forward government, industry and the community need to understand and accept that residual risk and liability will exist in successfully closed post-mined land. To ensure that mining is a temporary land use, mechanisms for improving relinquishment outcomes, explored in this paper, and innovative thinking around post-mining land uses must also be employed. This paper presents approaches to relinquishment, including risk and liability determination and post-closure funding arrangements throughout the mining lifecycle. When coupled with a defined regulatory process for relinquishment, these can drive better mine closure outcomes.
\end{abstract}

Keywords: mine closure, residual risk, closure liability, next land use, relinquishment

\section{Introduction}

The profile of mine rehabilitation and closure is gaining momentum in Australia, with an increasing focus by both governments and the community on range of mine closure related topics (Prior 2016). These include policy reviews on rehabilitation practices, mining regulation and financial assurance at Commonwealth, State and Territory levels.

This is driven by greater scrutiny of mining legacies, with an increasing list of poorly performing or abandoned mines in the public spotlight (Roche \& Judd 2016). Recent high profile planned closures of mines (and downstream industries) in New South Wales (Springvale Mine) and Victoria (Hazelwood Mine) have been criticised for failing to adequately provision for closure and as a result have the potential to impact the environment, as well as the surrounding communities (Coote 2017; Asher 2017).

An important part of mine closure policy in Australia is the pathway to tenement relinquishment, which facilitates the transition of mined land to an alternative land use. While examples of successfully relinquished mine operations can be found, there are a few examples in Australia that can be used as case studies (Department of Industry, Tourism and Resources (DITR) 2006; Department of Industry, Innovation and Science (DIIS) 2016; Butler \& Bentel 2011) to better understand how the process can be improved.

DIIS (2016) describes the aim of mine closure as "preventing or minimising adverse long-term environmental, physical, social and economic impacts, and to create a stable landform suitable for some agreed subsequent land use". Before exploring mine closure and the policies relating to relinquishment in further detail, it is useful to define some of the terms used throughout this paper. 
Mine closure occurs when the resource being exploited is depleted or it is financially unviable to continue mining (Laurence 2006). Closure should be a 'whole-of-mine-life-process', which ends with the relinquishment of mining tenure (Department of Mines and Petroleum (DMP) \& Environmental Protection Authority (EPA) 2015). It includes decommissioning of mining infrastructure and rehabilitation of land disturbed by mining activities, as well as mitigating social and economic impacts on internal and external stakeholders.

Relinquishment describes the transition of land to the next land manager or owner, generally a government department, following successful rehabilitation of disturbed land to an agreed standard. Relinquishment requires government 'sign off' which transfers responsibility (and liability) from the proponent to the next land user or manager (DMP \& EPA 2015). The term 'next landowner or manager' will be used interchangeably in this paper.

Next land use refers to an activity (or activities) that the land will be used for following cessation of mining operations (DMP \& EPA 2015). Next land use is a critical part of mine closure planning as the intended next use must be considered when determining specific mine closure outcomes.

In this paper, relinquishment will be used in the context of liability transfer following completion of rehabilitation activities to the satisfaction of the appropriate regulatory agencies.

\section{Literature and legislation}

The implications of closing a mine can have substantial environmental, social and financial impacts and mine closure represents a significant cost to the Australian mining industry. It also creates regulatory risk and liability for State governments, through both operating and abandoned mines, respectively (Peck \& Sinding 2009; Prior 2016; Audit Office of NSW 2017). The Department of Mines, Industry Regulation and Safety (DMIRS) estimates that Western Australia has a mine rehabilitation liability of approximately $\$ 3$ billion based on figures reported under the Mining Rehabilitation Fund Act 2012 (McKenna \& Martin 2018).

Policies such as the Mine Rehabilitation Fund (MRF) in Western Australia were established to provide the government with the financial means to address abandoned mines, while simultaneously freeing up capital for future investment in resource development through the release of mining tenement bonds (Gorey et al. 2016). The intention was to also incentivise the mining industry to undertake progressive rehabilitation to reduce their annual MRF levy contributions. Similar policies have been implemented in other States within Australia, however, there has not been a corresponding increase in successfully closed and relinquished mines in the country over the last five years.

\subsection{Relinquishment in the mining industry}

Successfully closed and relinquished mines in Australia are uncommon, with few examples evident in the literature. DIIS (2016) lists case studies, including Timbarra, Bottle Creek and Kestrel mines, however these are exceptions rather than the norm. Each case study provides a summary of the key activities that facilitated good closure outcomes, and ultimately enabled relinquishment of tenure. Analysis of these activities demonstrated the different pathways each mine took in order to achieve relinquishment, particularly with respect to legislative requirements. The few available case studies of relinquishment demonstrate that no clear pathway to relinquishment exists within mine closure policy in Australia (Finucane-Woodman 2017).

A review of the Australian literature on mine closure implementation reveals a focus on environmental outcomes, where achieving safe, stable, non-polluting and self-sustaining post-mining landscapes is the primary concern, with less consideration for socio-economic outcomes (Lamb et al. 2015; Laurence 2006). This environmental focus can partly be explained by reviewing mine closure policy in Australia, which gives greatest consideration to protection and restoration of the environment impacted by mining.

In contrast, the international literature on mine closure has a greater focus on the social and economic impacts caused when a mine closes (Cochilo 2002; Yakovleva et al. 2017). This is particularly true for mining in developing countries where mining operations employ significantly more people, at lower wages, and 
governments are less able to provide services to their citizens (Goh \& Effendi 2017; Kotsadam \& Tolonen 2016; Peck \& Sinding 2009). This lack of capacity within developing nation governments has resulted in legislative requirements for operating and closing mines in these jurisdictions that enforce the establishment of social and economic initiatives that benefit the employees and greater surrounding community (Marais 2013).

The three pillars of sustainability, first described by Elkington (1994) as the 'triple bottom line', are interesting when applied to mine closure. While environmental outcomes garner greater focus in mine closure literature in Australia, social and economic outcomes are more often cited in international mine closure examples. While policy and actions by the Australian mining industry can explain this trend, further consideration for how these three complimentary outcomes can be balanced and incorporated into mine closure and relinquishment is warranted.

\subsection{Snapshot of relinquishment policy in Australia}

Within Australia, legislative requirements for undertaking mine closure planning have been in place for some time, however the extent to which this applies varies across the States and Territories. It is now a common requirement that mine closure plans should be developed at the approval stage of a mine and that the closure planning process continues throughout the life of an operation (Cochilco 2002; Department of Environment and Heritage Protection (DEHP) 2014; NSW Department of Trade and Investment, Regional Infrastructure and Services (DTIRIS) 2013; DMP \& EPA 2015; Glenn et al. 2014).

While governments and mining companies abide by legislation, guidelines, internal standards and procedures with respect to mine closure planning throughout an operations life, there are limited examples within Australia of mines closing to the satisfaction of the respective government allowing relinquishment of mining tenure (DITR 2006; DIIS 2016; Lamb et al. 2015).

In Western Australia, specific guidance for relinquishment of mine tenure can be found in the Guidelines for Preparing Mine Closure Plans (DMP \& EPA 2015) with additional information on the DMIRS website (Finucane-Woodman 2017). Around Australia, there is similarly limited policy information on relinquishment provided by relevant regulatory agencies. In general, relinquishment policy is considered as the surrender of mining tenure that, while possible, does not address the issue of ongoing obligations or liability transfer.

Perhaps the most comprehensive guidance can be found in the Leading Practice Sustainable Development Program for the Mining Industry Handbook on Mine Closure, which includes case studies and a proposed flow chart for achieving relinquishment (DIIS 2016). The Northern Territory government website lists useful guidance material and forms, with the DIIS Handbook found in the mine closure and rehabilitation section. Although specific relinquishment guidance is provided in the Handbook, it is high level and is not supported by specific policy documents in any State or Territory within Australia.

\section{Roadblocks to relinquishment}

The lack of clear policy and legislative guidance for mine relinquishment has been established as one contributing factor to the limited examples found in Australia. While significant, inadequate policies are not the only challenge facing the government and the mining industry in achieving relinquishment.

Mining is often described as a transitional use of land, that once complete, enables an alternate utilisation of the land to occur (DIIS 2016). Unfortunately, this is seldom realised, due to most mines delaying closure, through cyclic mining activities based on changing resource size and commodity price, ongoing care and maintenance, divestment or abandonment, resulting in full mine closure rarely being implemented (Lamb et al. 2015).

To achieve relinquishment, consideration and planning for the next land use after mining needs to occur at early stages of a mining project. While post-mining land uses can change over time, particularly for long life mines, regular engagement with stakeholders can allow changing expectations to be integrated into the mine closure planning process. 


\subsection{Understanding closure requirements}

Typically, knowledge of rehabilitation and closure requirements increases at the early stages of a project as part of the approvals phase. It then gradually grows over the operating life of a mine until closure approaches and a rapid increase in knowledge occurs to enable closure to begin at the cessation of mining, principally driven by regulatory obligations, shown in Figure 1 (blue line). Unfortunately, this situation does not optimise the construction and operation of a mine (e.g. development of waste rock dumps and tailings storage facilities), resulting in limitations on how mining landforms can be rehabilitated and closed. One example is the placement of material in waste rock dumps, without consideration for final landform designs, often causing potentially acid forming material being present on the exterior and insufficient benign waste material available for encapsulation. This contributes to poor mine closure practices that significantly increase costs, limit post-mining land use options, and ultimately hinder relinquishment.

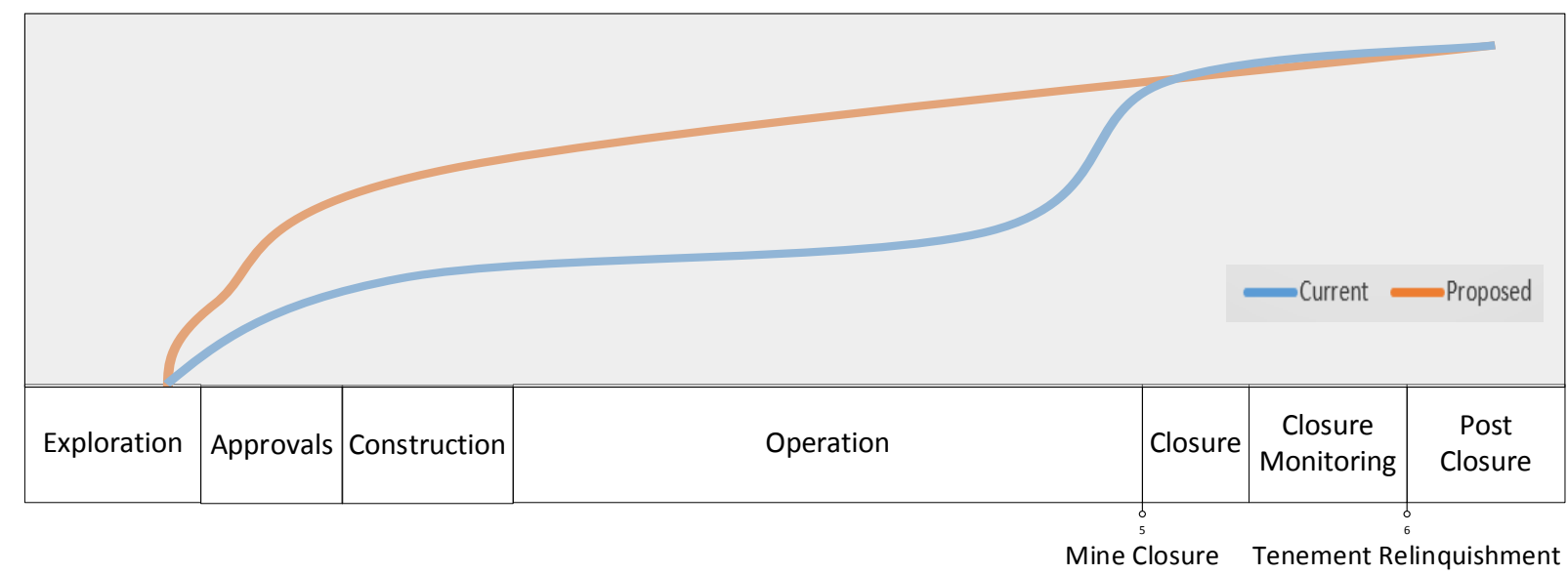

Figure 1 Current and proposed closure knowledge understanding across the mining lifecycle

An alternate approach (Figure 1, orange line), to maximise opportunities for operating a mine efficiently, reduce rehabilitation costs and enable a valuable post-mining land use is to increase closure knowledge to a high level as early in a project life as possible. Then gradually increase the knowledge through the operating phase, so that closure planning and progressive rehabilitation opportunities can be exploited throughout the mine life. This can allow engagement with stakeholders early in a project life to begin the process of achieving agreement on post-mining land use with the next landowner. With a clear post-mining land use defined upfront, this can be integrated into the decision-making and mine planning process during construction and operation to reduce residual risk and generate opportunities together with the next landowner.

\subsection{Residual risk and liability}

Another challenge to achieving relinquishment is the reality that residual risk and the associated liability will exist in most successfully closed mines (Mackenzie 2016). This becomes a roadblock when discussions begin with the next land manager, particularly if this is a regulatory department that is risk averse and already stretched for budget and resources. In a Western Australian context, the Department of Planning, Lands and Heritage (DPLH) manages $92 \%$ of the State's land and is most likely to be responsible for post-mined land (Australian Government 2018). The question must be asked: what is the incentive for another party to assume responsibility for land that has been materially impacted by mining, particularly where specific policy guidance is lacking?

Government, industry and the community need to understand and accept that residual risk and liability will exist in successfully closed post-mined land. To ensure that mining is a temporary land use, mechanisms for improving relinquishment outcomes and innovative thinking around post-mining land uses must be employed. 


\subsection{Mining value proposition}

It's useful to consider mining, and the land used for it, from a value generation perspective. Figure 2 depicts the current and an alternate value proposition across the mining lifecycle. Exploration, while costing money to undertake, also generates value through development of future investment returns. Once an economic resource is justified and the project moves into approval and construction phase the asset generates a negative value due to the large amount of capital invested to build an operating mine. In operation, the mine generates a profit, until the resource is eventually exploited and profits cease. It is widely accepted that closure and even post-closure phases of a mine do not generate any value.

Current value proposition

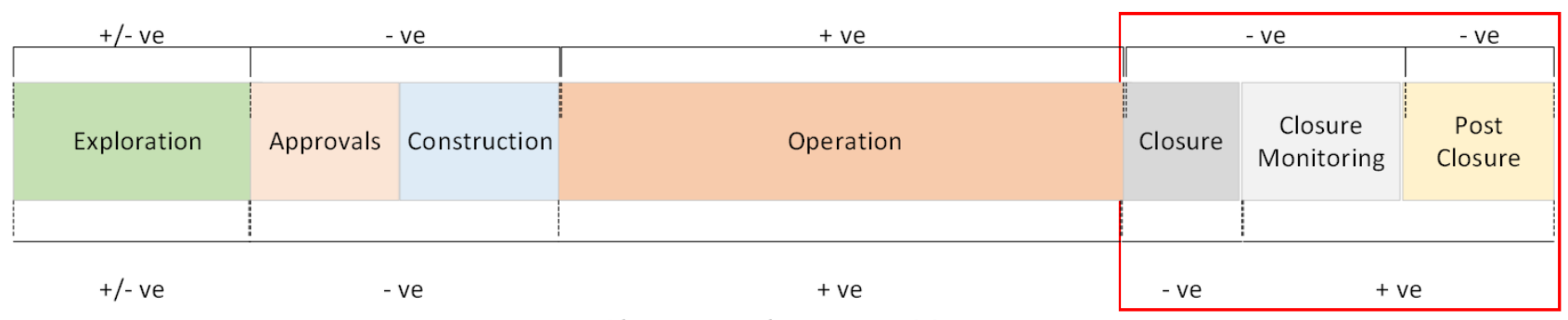

Alternate value proposition

Figure 2 Current and alternate value propositions across the mining lifecycle

Assuming value can be generated after the cessation of mining could positively impact decision-making leading up to closure. It would also make engaging with the next land manager easier, as the conversation would focus on value creation and transfer, rather than residual risk and liabilities. Value can be generated in a number of ways and will be determined somewhat by the next land manager. This could include the value of land, for grazing and agriculture purposes, or the assets left behind, such as rail infrastructure, power station, or runway.

\subsection{Investing in closure}

Ultimately, mine closure is an investment decision, approached in the same way that all major mining investment decisions are made. For stock-listed companies, mining executives are accountable to the board and shareholders, with an expectation that investment decisions are fiscally responsible and generate shareholder value. In a relinquishment context, investment in mine closure is done to meet regulatory requirements, achieve internal company standards and most importantly allow the transfer of liability associated with the closed mining tenements. In the absence of certainty regarding the relinquishment process, closure investment does not allow the transfer of liability, thus creating a situation where senior mining company decision makers are reluctant to implement closure of a mine.

\section{$4 \quad$ Mechanisms for achieving relinquishment}

\subsection{Provisioning relinquishment}

It's widely accepted that residual risk exists, even for successfully closed mines (Bocking et al. 2009). As noted in Section 3.2, residual risk can create a liability that the next landowner will be responsible for. While this varies greatly between mining projects, it is likely that costs will be incurred to effectively manage the liability into the future. This could include expenses for monitoring groundwater or mine voids, treatment of contaminated landform leachates, and remediation of rehabilitation failures (Bocking \& Fitzgerald 2012). One mechanism to account for liability and associated management actions after the successful closure of a mine is to establish a fund that can be used to pay for these potential expenses. There are examples of postclosure funding mechanisms being established in Australia, Papua New Guinea, and Indonesia (Mackenzie 2016). 
Figure 3 depicts the typical mining lifecycle, with key milestones, and the typical liability ownership between the State and mining company in an Australian context. Simplified for the purposes of illustration, liability ownership can also include several other parties, such as freehold title landowners, pastoral leaseholders and Traditional Owners (TOs). The upper brackets of the figure show the possible funding mechanisms that apply at different stages of a mining project tenure. During operations financial assurance is required by the relevant mining regulatory authority in the form of bonds, bank guarantees or annual levies, such as Western Australia's MRF levy. Once mine closure has been completed, monitoring has demonstrated achievement of closure objectives (completion criteria) and the regulator agrees to sign off on obligations being met, relinquishment of tenure can occur. There is however residual risk and liability remaining that would transfer back to the State, or to another landowner at this time. This is the point in which a post-closure trust fund (PCTF) would finance the cost of managing the land post-mine closure.

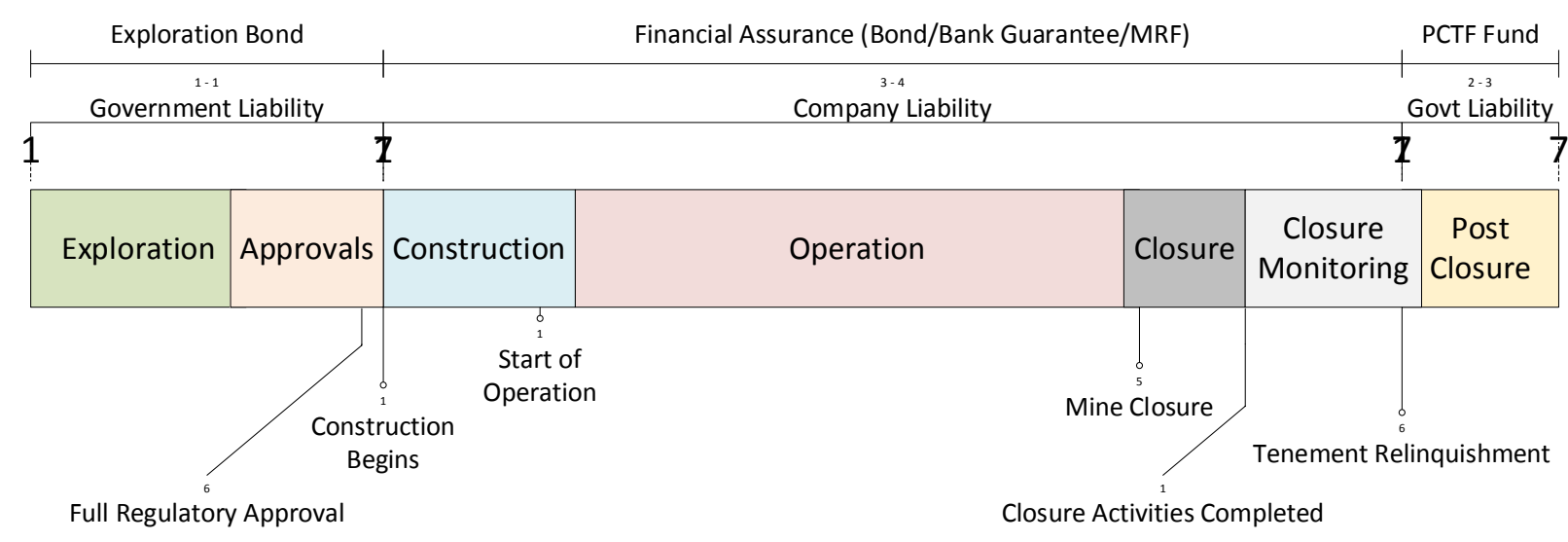

Figure 3 Mining lifecycle depicting key milestones and liability ownership over time. Possible funding mechanisms across the mining lifecycle are also displayed

In Australia, establishment of a post-closure trust fund has occurred in Victoria for the Stockman copper-zinc mine in 2017. This serves as a possible model for other mining operations in the future. The trust fund will provide monies to cover the cost of monitoring and maintaining the tailings storage facility following successful closure and relinquishment. To calculate the principal fund amount the anticipated post-closure monitoring and minor maintenance activities were costed over an agreed time period. An additional sum was also included to cover insurance fees for residual property and environmental liabilities (Earth Resources Regulation 2018).

The proposed process for agreement and establishment of the post-closure trust fund includes three major components:

1. Determination of residual risk post successful closure.

2. Calculation of liability associated with residual risk.

3. Establishment of a post-closure trust fund.

It is possible that not all sites will require establishment of a post-closure trust fund, based on the residual risk and agreed liability. The calculation of liability should be offset against the value of remaining assets and the land value to determine the size of any post-closure fund. The advantage of adopting the process outlined, is in getting the next land manager involved in understanding and ultimately agreeing on the final potential liability/value to determine a path towards successful mine closure. Incorporation of this funding mechanism into closure provisioning could provide a solution to meaningful engagement with the next land manager that facilitates eventual relinquishment. 


\subsection{Policy options}

Legislative guidance exists for the development of mine closure plans, establishment of completion criteria and the surrender of tenements in Australia. However, the focus is on tenement specific obligations and is typically administered by the government department responsible for resource development. Policy direction is lacking with respect to government departments that will ultimately assume responsibility for post-mined land in most cases.

Addressing this current policy gap is critical to enabling future relinquishment of successfully closed mines. DMIRS have made some progress to developing an interagency solution for relinquishment, with acknowledgement of the important role that other agencies play in achieving successful closure. The key to providing clarity for the mining industry is defining the role relevant agencies have before, during and after mining, so that the right stakeholders can be engaged.

Consideration must also be given to what successfully closed mining land will revert to from a land tenure perspective. Generally, only a small portion of a mining tenement is significantly impacted by mine voids or landforms, the remaining land is left untouched or only minimally disturbed. This portion of the land is readily rehabilitated and can more easily be returned to its previous use. This creates the greatest opportunity for repurposing the land and generating future value.

In Western Australia, responsibility for assuming ownership of post-mined land is determined by the underlying land type, commonly crown land. One option is the creation of a reserve, with a management action assigned to the most relevant government agency capable of managing the site, for example DMIRS. Having a department, such as DMIRS, with understanding of the resource sector being responsible for the management of a successfully closed mine may be preferable to a department with limited understanding of post-mining liabilities. The problem of funding activities associated with relinquished mine sites still exists, however this can be addressed by the establishment of a PCTF.

One mechanism for managing PCTF exists already, namely the MRF. While specifically for the purposes of addressing abandoned mines, the structure and its administration by DMIRS, is a useful model to consider for management of funds associated with relinquished mine tenure.

A clear interagency pathway to achieve relinquishment, supported by policy, will give mining executives enough certainty for making mine closure investment decisions. This could remove a major existing impediment to successful closure and relinquishment, while positively impacting closure planning across the mining lifecycle.

\subsection{Post-mining value generation}

Smith (2009) concluded that early, broad stakeholder engagement and successful closure implementation can allow the transfer of capital, generated during the mining process, to future generations after relinquishment. This is an important concept that recognises the significant socio-economic benefits created by mining projects. Rather than leaving a liability for future landowners, successfully closed mines can provide opportunity and generate future value.

The challenge for government and the mining industry is to develop processes that unlock opportunities and create value in landscapes following mining. The key to framing potential value is the selection of post-mining land uses that challenge the status quo of returning the land to its pre-mining (modified) condition. When viewed in the context of value generated during mining operations, coupled with the potential risk and liability left by closed mining landforms and voids, the pre-mining land use, such as return to unallocated crown land, the value proposition is unlikely to be attractive to the next landowner. By exploring alternative land uses that could drive greater value, it is possible to increase the attractiveness of post-mined land.

Figure 4 depicts the conceptual value generated through four different land use scenarios across the mining lifecycle. Value is defined in this figure as revenue generation from the use of the land based on possible activities, such as mining, pastoralism or conservation (e.g. tourism). Other types of value, such as aesthetic 
beauty, cultural heritage or ecological function have not been considered here, however can represent significant value in addition to revenue generation. In Figure 4 value generation of land used for conservation, pastoralism or other non-mining activities declines during the development and operation of a mine. Inversely, value generation increases as a mine enters operational phase, before reducing as the resource is exploited. In the figure, the land use trajectory decision point, occurring during the closure implementation phase, shows a return to positive revenue generation depending on which land use scenario is selected. Scenario 2 is used as a baseline, where a typical land use, in this case pastoralism, shifts to mining, and then once the resource is depleted, returns to original, modified land use. Scenario 1 describes the practice of care and maintenance or poor mine closure practices where value is destroyed and doesn't return to a positive. Scenario 3 is less common and demonstrates the value that can be created by selecting and returning the land to a use that support conservation outcomes, such as tourism or carbon farming. Scenario 4 describes novel post-mining land uses that utilise a combination of activities that become additive, where pastoralism, conservation and innovative uses, like renewable energy projects, deliver greater value than the original land use.

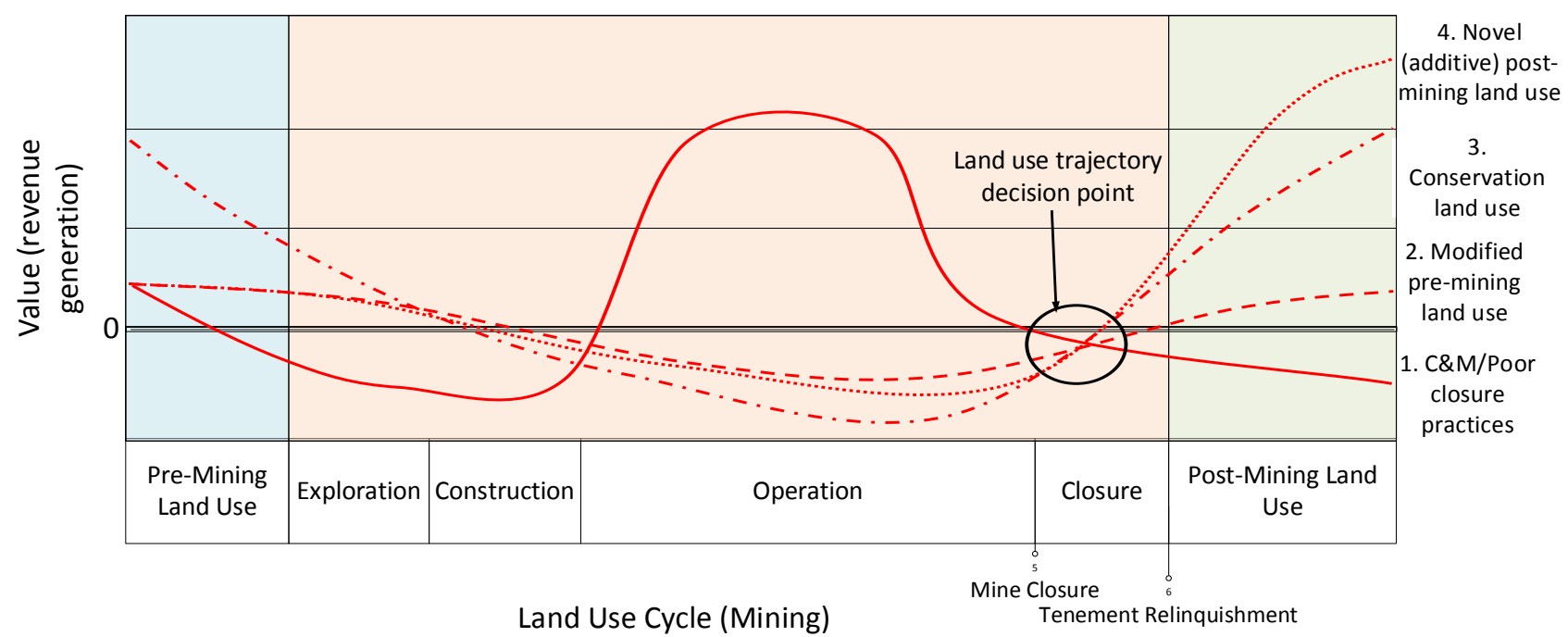

Figure 4 Value generation for four land use scenarios across the mining lifecycle. Following cessation of mining and during implementation of closure all scenarios could potentially be achieved

Achieving novel, additive post-mining land uses requires innovative thinking on behalf of all stakeholders and is likely not, nor should it be, core business for mining companies. The opportunity lies in attracting niche industries to propose novel post-mining land uses that make the most out of remaining assets, post-closure funding mechanisms, and unique landscapes and ecologies of successfully closed mines.

\section{Conclusion}

Effective mine closure planning at all stages in the operational life of a mine is critical to ensure that successful closure outcomes are achieved and the cost of closure (liability) is known, accounted for and minimised where possible. Integrating mine closure into 'life-of-mine' plans can improve rehabilitation success and reduce liability.

In the case of a successfully closed mine, there should be particularly low levels of liability, however it is likely that some residual risk exists. While the process may be understood generally, the policy and guidelines enabling relinquishment are not always clear or include multi-agency collaboration.

Specific policy guidance on relinquishment will enable mining companies to invest in closure, maximising post-mining land use opportunities. This requires companies to gain a thorough understanding of closure requirements at an early project stage, along with engaging stakeholders throughout the mining lifecycle. Acknowledgement of residual risk, calculation of liability and the adoption of post-closure funding mechanisms will make conversations between a mining company and the next land manager an easier 
proposition. Finally, changing the way value is measured and generated after mining ceases will enable relinquishment to open up opportunities for future generations.

\section{Acknowledgements}

The author would like to thank Grant Wardell-Johnson, Dave Kendal and Vanessa McDonald and everyone who gave their time and advice during the development of this paper.

This research was supported by the Australian Government through the Australian Research Council Industrial Transformation Training Centre for Mine Site Restoration (Project Number ICl150100041). The views expressed herein are those of the authors and are not necessarily those of the Australian Government or Australian Research Council.

\section{References}

Asher, N 2017, Hazelwood Rehabilitation Estimated to Cost $\$ 743$ Million but May Rise, Engie Says, ABC Gippsland, http://www.abc.net.au/news/2017-01-20/hazelwood-rehabilitation-to-cost-743-million-engie-says/8197784

Audit Office of NSW 2017, Mining Rehabilitation Security Deposits, NSW Auditor-General's Report, viewed 2 February 2019, https://www.audit.nsw.gov.au/our-work

Australian Government 2018, Crown Land in Western Australia, Australian Government, https://www.austrade.gov.au/landtenure/land-tenure/crown-land

Bocking, KA \& Fitzgerald, P 2012, 'Management and financing of post-closure liabilities', in AB Fourie \& M Tibbett (eds), Proceedings of the Seventh International Conference on Mine Closure, Australian Centre for Geomechanics, Perth, pp. 49-56.

Bocking, KA, Kam, SN, Welch, DE \& Williams, DA 2009, 'Management of mine sites after closure', in AB Fourie \& M Tibbett (eds), Proceedings of the Fourth International Conference on Mine Closure, Australian Centre for Geomechanics, Perth, pp. 245-252.

Butler, H \& Bentel, GM 2011, 'Mine relinquishment - process and learnings', in AB Fourie, M Tibbet \& A Beersing (eds), Proceedings of the Sixth International Conference on Mine Closure, Australian Centre for Geomechanics, Perth, pp. 3-12.

Cochilco, CCC 2002, Research on Mine Closure Policy, retrieved from Mining, Minerals and Sustainable Development (MMSD), International Institute for Environment and Development (IIED).

Coote, G 2017, Calls for Urgent Intervention to Prevent Closure of Key NSW Coal Mine and Power Station, ABC Central West, http://www.abc.net.au/news/2017-09-20/calls-for-urgent-action-to-secure-future-of-key-nsw-coal-mine/8962618

Department of Environment and Heritage Protection (DEHP) 2014, Rehabilitation Requirements for Mining Resource Activities, Queensland Government.

Department of Industry, Tourism and Resources (DITR) 2006, Mine Closure and Completion: Leading Practice Sustainable Development Program for the Mining Industry, viewed 9 February 2019, https://nt.gov.au/_data/assets/pdf_file/0015/ 203415/mine-closure-and-completion.pdf

Department of Industry, Innovation and Science (DIIS) 2016, Mine Closure: Leading Practice Sustainable Development Program for the Mining Industry, viewed 15 January 2019, https://www.industry.gov.au/resource/Documents/LPSDP/LPSDP-Mine ClosureCompletionHandbook.pdf

Department of Mines and Petroleum (DMP) \& Environmental Protection Authority (EPA) 2015, Guidelines for Preparing Mine Closure Plans, Department of Mines and Petroleum \& Environmental Protection Authority, Perth.

NSW Department of Trade and Investment, Regional Infrastructure and Services (DTIRIS) 2013, ESG3, Mining Operations Plan (MOP) Guidelines, NSW Department of Trade and Investment, Regional Infrastructure and Services, Maitland.

Earth Resources Regulation 2018, Stockman Project: Site Rehabilitation and Post-closure, Victorian Government, http://earthresources.vic.gov.au/earth-resources-regulation/information-for-community-and-landholders/stockmanproject/site-rehabilitation-and-post-closure

Elkington, J 1994, 'Towards the sustainable corporation: win-win-win business strategies for sustainable development', California Management Review, vol. 36, no. 2, pp. 90-100.

Finucane-Woodman, M 2017, Mining Tenure Relinquishment in Western Australia: Current and Future Directions, master's thesis, Murdoch University, https://www.academia.edu/36167392/Mining_Tenure_Relinquishment_in_Western_Australia_ Current_Practice_and_Future_Directions

Glenn, V, Doley, D, Unger, C, McCaffrey, N, McKenna, P, Gillespie, M \& Williams, E 2014, 'Mined land rehabilitation: is there a gap between regulatory guidance and successful relinquishment?', AusIMM Bulletin, June 2014, pp. 48-54.

Goh, E \& Effendi, S 2017, 'Overview of an effective governance policy for mineral resource sustainability in Malaysia', Resources Policy, vol. 52(2017), pp. 1-6.

Gorey, P, McHenry, M, Morrison-Saunders, A, Mtegha, H \& Doepel, D 2016, 'Critical elements in implementing fundamental change in public environmental policy: Western Australia's mine closure and rehabilitation securities reform', Australasian Journal of Environmental Management, vol. 23, no. 4, pp. 370-381.

Kotsadam, A \& Tolonen, A 2016, 'African mining, gender, and local employment', World Development, vol. 83(2016), pp. 325-339. 
Lamb, D, Erksine, PD \& Fletcher, A 2015, 'Widening gap between expectations and practice in Australian minesite rehabilitation', Ecological Management and Restoration, vol. 16, no. 3, pp. 186-195.

Laurence, D 2006, 'Optimisation of the mine closure process', Journal of Cleaner Production, vol. 14(2006), pp. $285-298$.

Mackenzie, S 2016, 'Post-closure funding initiatives to facilitate custodial transfer and relinquishment of mining tenure', in AB Fourie \& M Tibbett (eds), Proceedings of the 11th International Conference on Mine Closure, Australian Centre for Geomechanics, Perth, pp. 419-422.

Marais, L 2013, 'Resources policy and mine closure in South Africa: the case of the Free State Goldfields', Resources Policy, vol. 38(2013), pp. 363-372.

McKenna, M \& Martin, P 2018, Mining Rehabilitation in Western Australia - Where to From Here?, blog post, viewed 26 July 2019 , https://www.gtlaw.com.au/insights/mining-rehabilitation-western-australia-\%E2\%80\%93-where-here

Peck, P \& Sinding, K 2009, 'Financial assurance and mine closure: stakeholder expectations and effects on operating decisions', Resources Policy, vol. 34(2009), pp. 227-233.

Prior, E 2016, 'Mining \& petroleum closure \& rehabilitation: material obligations - a critical spotlight on costs \& provisions/energy analysis/mining \& metals analysis', Citi Research Closure \& Rehabilitation in the Spotlight, Citi Research.

Roche, C \& Judd, S 2016, 'Ground truths: taking responsibility for Australia's mining legacies', Mineral Policy Institute, http://www.mpi.org.au/2016/06/grond-truth-taking-responsibility-for-australias-mining-legacies/

Smith, B 2009, 'Mining for Closure', PhD dissertation, UNSW Sydney, https://www.be.unsw.edu.au/sites/default/files/ upload/pdf/schools_and_engagement/resources/notes/5A3_16.pdf

Yakovleva, N, Kotilainen, J \& Toivakka, M 2017, 'Reflections on the opportunities for mining companies to contribute to the United Nations Sustainable Development Goals in sub-Saharan Africa', The Extractive Industries and Society, vol. 4(2017), pp. 426-433. 